the spiracle is oval and a short distance off the cephalic margin. The same otherwise. Mandibles 4-dentate.

Described from one female on a tag in the U. S. National Museum from Franconia, N. H.

Type: Catalogue No. 20427, U. S. National Museum, the female on a tag, a caudal leg and the head on a slide.

\title{
A NEW SPECIES OF THE GENUS MYMAR FROM THE WOODS OF MARYLAND WITH AN IMPORTANT DESCRIPTIVE NOTE.
}

\author{
By A. A. Girault, \\ Bureau of Entomology, Washington, D. C. \\ Mymar cincinnati sp. nov.
}

Male: Similar to venustum (female type) but the antennæ are entirely black, the base of the blade of the fore wing is rather broadly infuscated, there are on the fore wing 43 primary marginal cilia (instead of 34), the midlongitudinal line of discal cilia runs from apex nearly to the base of the blade (instead of into the costal margin, farther from base); and most of the discal cilia of the fore wing are caudad of the midlongitudinal line instead of cephalad as in the other species. Scape long, curved; flagellar joints elongate, subequal, 2 eight times (or more) longer than wide.

One male captured by sweeping grass in an open wooded bog, Glenndale, Md., August.

Type: Catalogue No. 20468, U. S. National Museum, the specimen on a slide.

Mymar venustum has the caudal wing shaped like a long thick bristle with the hooklets at its apex. In the above new species it is similar but prolonged beyond the hooklets in the form of a hair as long as the part from base to the hooklets and after that length widening into a very linear blade of more than half the length of the hairlike pedicel and which bears a few long marginal cilia caudad. In Mymar, then, the hind wing has a short, very linear blade on a long pedicel while the petiole of the wing (from base to hooklets) is much longer than in the other genera. This blade part of the wing must break off easily and this accounts for 
its absence in venustum. In the Australian M. tyndalli, the bladelike portion of the caudal wing was absent. Neomymar has normal hind wings except that the petiole is long as in Mymar.

\section{A METALLIC SPECIES OF CIRROSPILOPSIS FROM MARYLAND (HYMENOPTERA EULOPHIDA).}

By A. A. Girault, Bureau of Entomology, Washington, D. C.

The following species resembles a Diaulinopsis but there are no grooves on the scutellum, the caudal tibial spur is single and the club without a distinct apical nipple.

Cirrospilopsis metallicus sp. nov.

Female: Length, $1.10 \mathrm{~mm}$. Brassy metallic green, the wings hyaline, the legs (except the coxæ; apex of first coxæ yellow), venation and the antennæ (except the scape and pedicel except both at apex), golden yellow. Body densely scaly, the parapsidal furrows distinct, the propodeum moderately short, noncarinate (a median carina subobsolete), the spiracles small, rounded, cephalad. Bristles on thorax minute, sparse. Postscutellum rather large. Mandibles 4-dentate, the last two teeth much smaller than the others. Pedicel subequal to funicle 1 which is nearly twice longer than wide, 2 somewhat shorter, the club somewhat longer than the funicle; ring-joints distinct. Middle tibial spur long, slender. Stigmal vein not quite half the length of the marginal, the postmarginal two-thirds the length of the marginal.

From two females captured by sweeping in the woods, Glenndale, Md., May 4, 1916.

Types: Catalogue No. 20291, U. S. National Museum, the specimens on a tag, a head and two caudal tibiæ on a slide. 

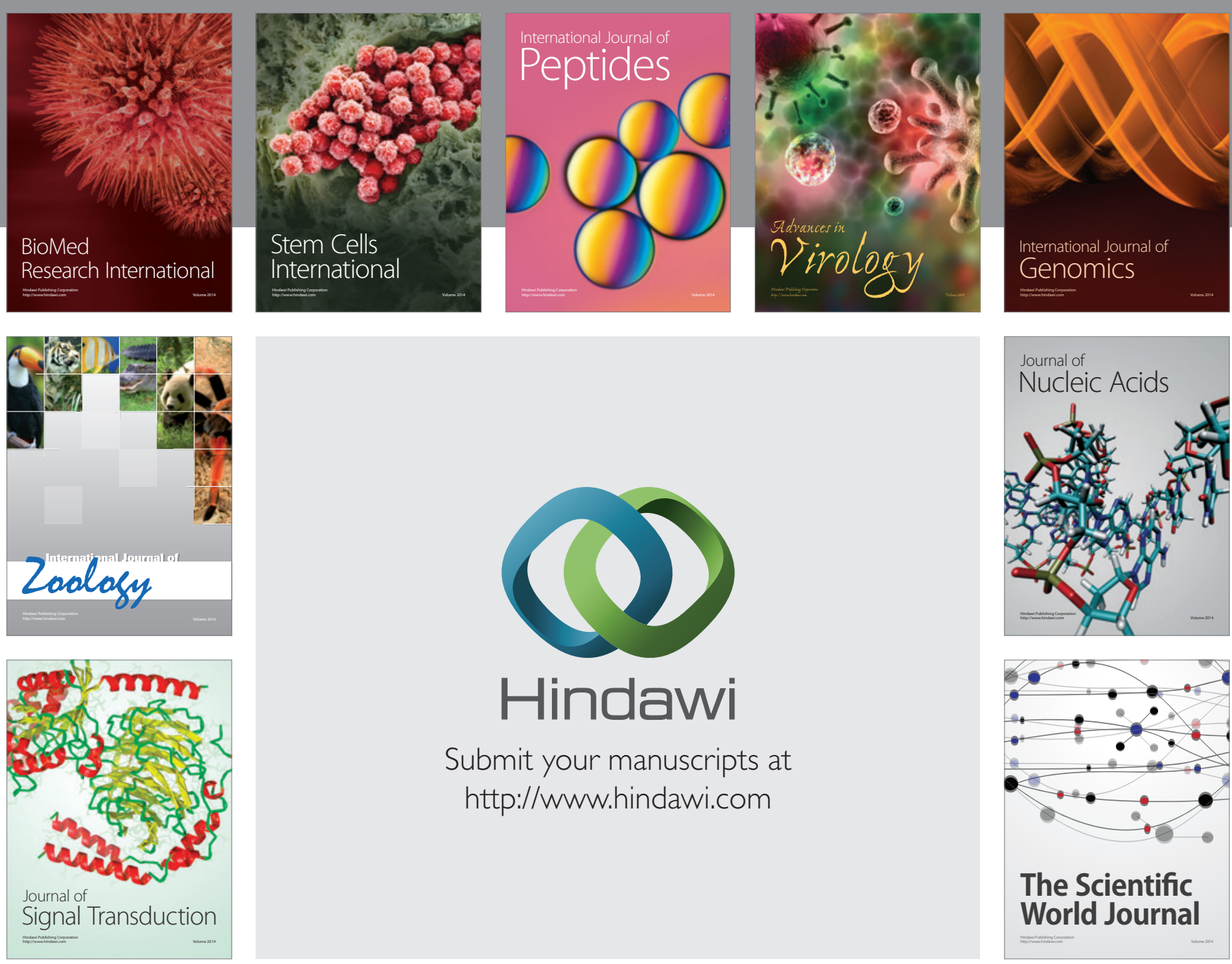

Submit your manuscripts at

http://www.hindawi.com
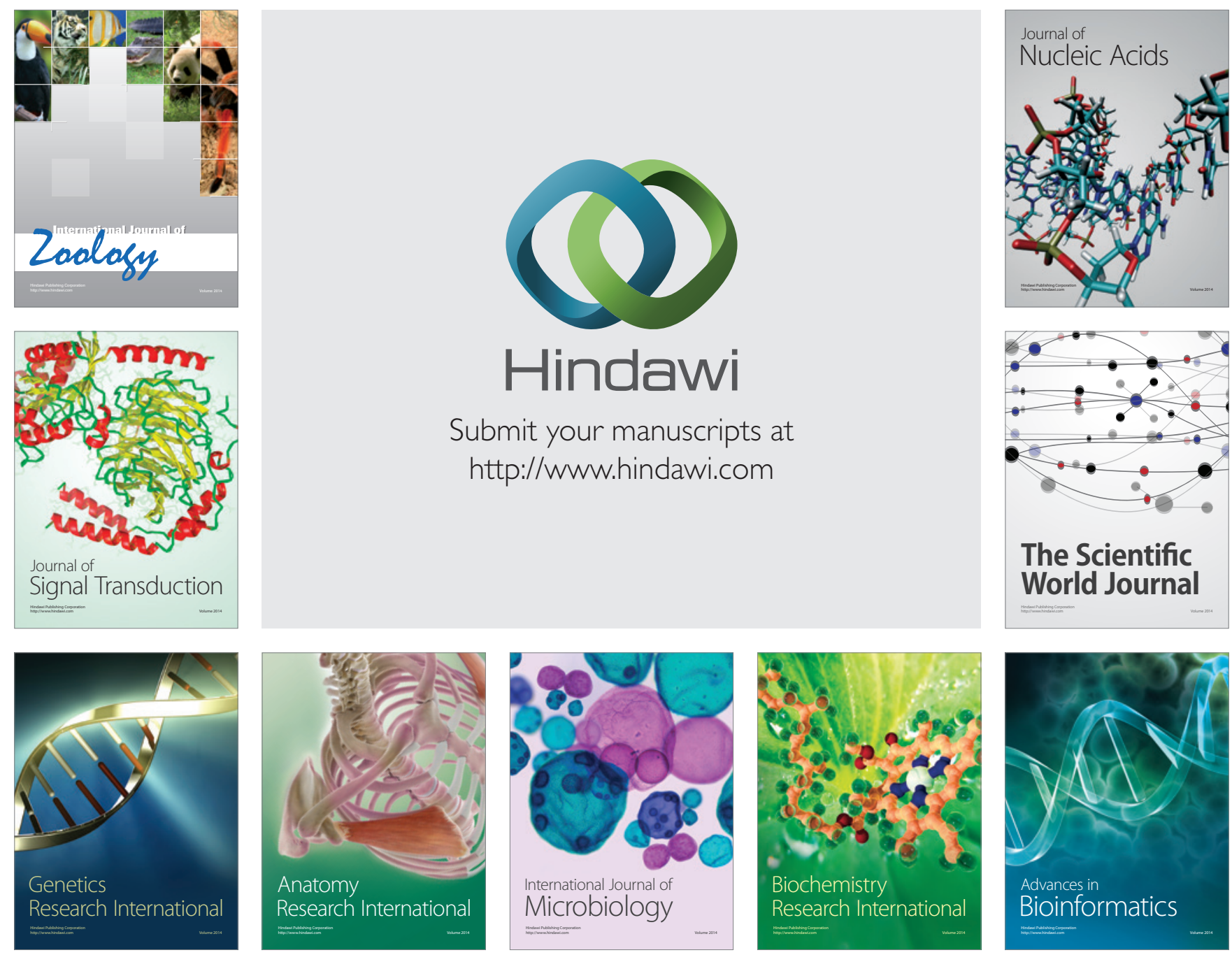

The Scientific World Journal
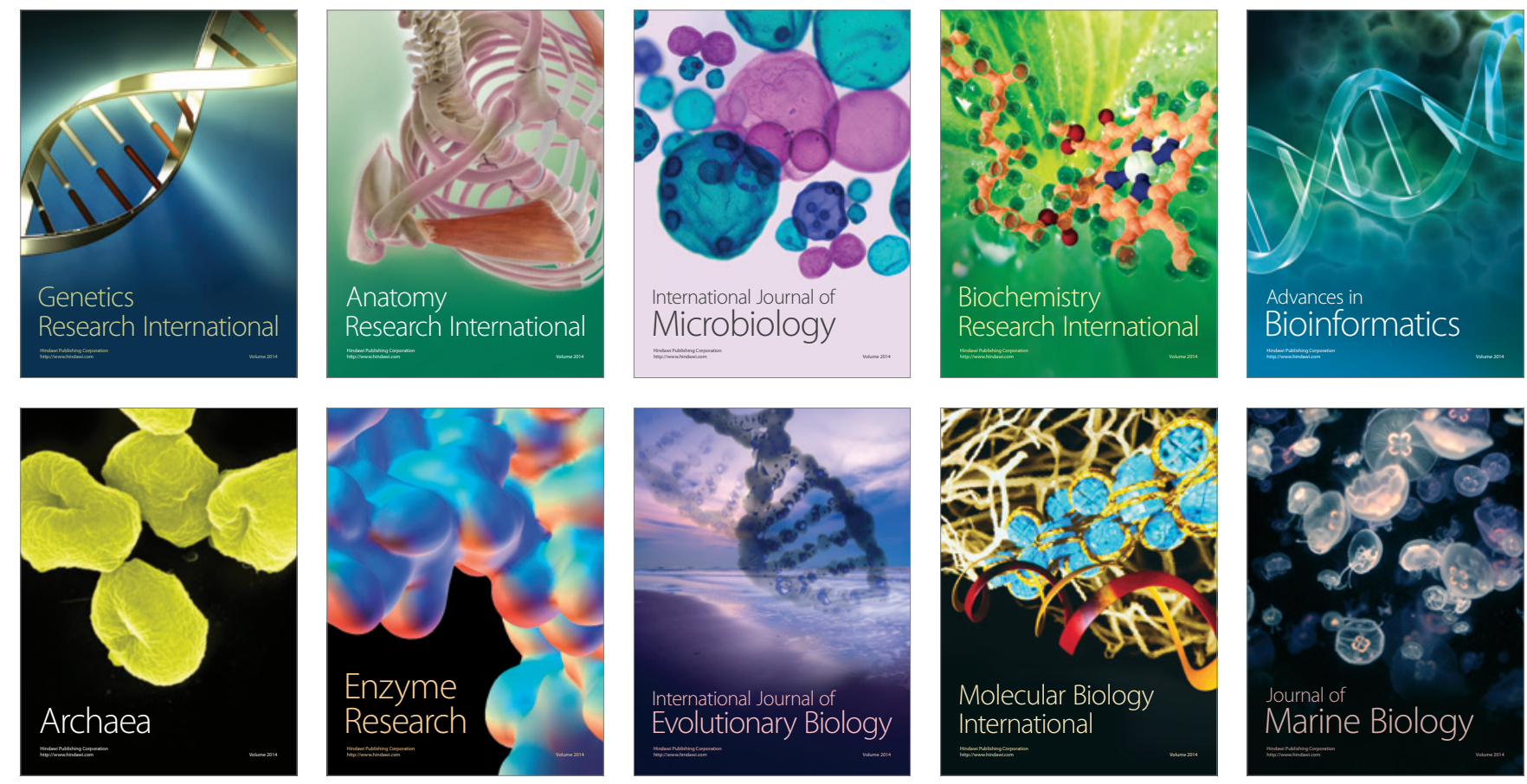